\title{
Green Computers
}

\author{
This paper, selected for the category "Best papers from 1959 to 2008", \\ was first published in WIRTSCHAFTSINFORMATIK 36(6)1994:600-603.
}

\section{DOI 10.1007/s12599-008-0012-5}

\author{
The Author \\ Dipl.-Phys. Stephan W. Eder \\ Franz-Linz-Str. 13 \\ 53175 Bonn \\ Germany \\ stephan.w.eder@t-online.de
}

This article is also available in German in print and via http://www.wirtschafts informatik.de: Eder SW (2008) Grüne Computer.WIRTSCHAFTSINFORMATIK. doi: 10.1007/11576-008-0117-y.

\section{1 "Blue Angel" for the Eco-PC}

If new computer hardware until now has mostly been sold under the slogan "faster, better, higher", this has changed meanwhile: Also in the computer industry "environment" is now the magic word. Just about no manufacturer nowadays still dares to launch products without the energy label "Energy Star" of the U.S. American Environmental Protection Agency (EPA). Many companies at least offer devices they call "environmentally friendly". At the IT fair CeBIT 1995 a whole exhibition hall shall be devoted to the topic of "Green Computers". Also, the upcoming electronic waste and scrap ordinance has induced some companies to intensify development towards an environmentally sound PC.

Since July 1994 products can be audited by the "Jury Umweltzeichen" ("Environmental Label Jury"), which has developed terms for the award of the "Blue Angel" for environmentally designed computers as RAL-Gütezeichen (Jury Umweltzeichen 1994) ${ }^{1}$. The quality symbol will appear as a blue-white dot. The first official eco-PC, fulfilling these terms, is to be expected

\footnotetext{
The RAL is the abbreviation of RAL-German Institute for Quality Assurance and Certification, which is managing the awarding process in practice. The RAL awards a lot of quality labels, i. e. "Gütezeichen", for the German industry, one of them is the "Blue Angel".
}

before the expiration of 1994. In the computer eco-test of the German "Bund für Umwelt und Naturschutz" (BUND, the German union for environmental protection and conservation) in May 1994, SNI (Siemens Nixdorf, now Fujitsu Siemens Computers) and the Taiwanese manufacturer Acer have performed best. Here, the environmentalists not only examined computers on their own, but the complete $\mathrm{PC}$ product range and the environmental activities of the manufacturers.

Three criteria mark environmental friendliness:

- avoidance or reduction of materials and radiation, which are harmful to the environment and dangerous to health,

- construction, use of materials and packaging that facilitate recycling easy as well as

- economical use of energy and resources.

\section{Pollutants and radiation}

\subsection{Environmentally hazardous and unhealthy materials}

Computers worldwide have to comply with certain fire protection regulations. As long as materials are used for inflammable printed circuit boards, the electronic components mounted on the printed circuit boards and the circumjacent housing need an appropriate flame protection. Electronic components consist of a heterogeneous mixture of materials, containing a lot of metals und partly rare and high quality substances. The plastics used to guarantee the demanded properties for the necessary functionality or resulting from standards contain certain hazardous additives.

The best known environmental "toxins" in plastics are the brominated flame retardants. A long time polybrominated diphenyl ethers and biphenyls were used and are still used, unfortunately - as flame inhibitors in printed circuit boards, coating of electronic components und plastic housings. These substances release dioxins and furans even during manufacturing and at normal operating temperature - and not only during fires - so that they should be replaced as soon as possible. A provisional replacement is tetrabromobisphenol A (TBBPA). This flame retardant still contains bromine, and therefore a problematic substance seen from the viewpoint of health and recycling, but the highly poisonous fumes in conventional use are omitted. The protection of health therefore is satisfactory. From TBBPA another problem arises because antimontrioxide is added to increase effectivity, which has clearly proven a carcinogenic substance in animal tests. A further possibility for flame retardance are phosphorous compounds. They have the advantage not to be emitted in case of fires - in contrary to TBBPA. However, appropriate products are not on the market yet (October 1994).

When searching for environmentally friendly flame retardants one has to differentiate between the housing components on the one hand and the printed circuit boards and the electronic components on the other hand. Housings are produced either from metal or from plastics - mostly from polycarbonates and ABS (Acrylnitril-Butadien-Styrol) with TBBPA as flame retardant. For the printed circuit boards and the electronic components special plastic substances are used, which - like the black packaging compound - are produced worldwide by few, mainly foreign manufacturers. Regrettably, there is no transparency in this highly competitive market, to the disadvantage of environmentally friendly solutions.

In 1993, the company LOEWE took a step in another direction with their first "Eco-TV" (Fig. 1), in which a ceramic printed circuit board (substrate "rubalit") consists of $96 \%$ aluminum oxide (alumina) (Behrend 1994). It needs no flame retardant und additionally the disposal is unproblematic. Also spontaneously 


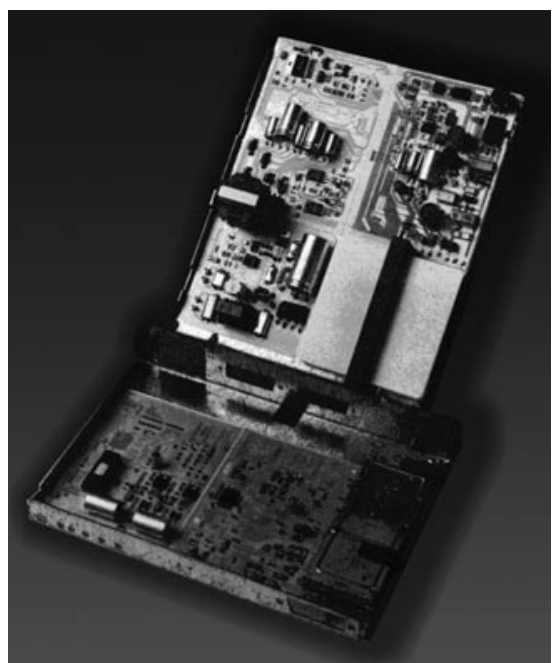

Fig. 1 Ceramic printed circuit board of the LOEWE ECo-TV

inflammable electronic components like foil transistors cannot ignite the printed circuit board. According to the company a flame retardant is no longer needed for the coating of the components. But according to Siemens Nixdorf (SNI) the ceramic, used routinely in microchip technology as substrate, is not applicable for printed circuit boards in computers because these boards have up to ten conduction layers.

Flame retardants are also of importance with the "Blue Angel". The quality mark is only awarded, if polybrominated diphenyl ethers and biphenyls are totally dispensed in the computer housings. The ban does unfortunately - not apply to printed circuit boards despite the printed circuit board described. As a survey from the BUND has shown, most manufactures are not using these materials any longer or they are currently converting to TBBPA (Eder 1994). Furthermore, no carcinogenic substances may be added to the housing materials for flame retardance, so the addition of anitomontrioxide is excluded.

Another substance seen as critical by environmental activists is polyvinyl chloride (PVC). A long time after the complete abandoning of PVC production including the underlying chlorine chemistry was demanded, people now just speak of "conversion" (n. a. 1994). This means that chlorine chemistry itself and chlorine are replaced by other synthesis technologies or replacement substances and products as far as possible. In construction engineering and for special purposes PVC is indispensible for the time being. The ongoing use of PVC in computer hardware is justified by the fact that the used PVC makes a flame retardant unnecessary, that it is reasonably priced and recyclable. But while housings can - as described above - be produced from other materials, no abdication of PVC for cable coating is in sight. Although LOEWE uses harmless polyethylene coating at the mentioned eco-TV, polyethylene does not fulfill all regulations of the flame retardant grades, which computers have to pass. Especially in the United States very strict flame protection regulations are in effect the so called UL (Underwriters Laboratories) standards.

Another environmental problem is the use of heavy metals especially in displays. While lead use in batteries for example is meanwhile replaced by nickel cadmium compounds, there are still no alternatives for the lead used in tin solder and for the inner coating of monitors. Glass from used displays is therefore highly plumbiferous. Because a true re-use is impossible, it ends up in road foundations.

\subsection{Radiation}

Monitors for the "Blue Angel" have to comply with the Roentgen ordinance and the MPR II-standard for electric and magnetic fields of the Swedish health ministry. The compliance meanwhile is secured by all displays, even no name products. However, it has to be considered that the shielding of the fields according to MPR II is only mandatory to the "front", that means in the direction of the user. The common placement of office desks "two desks opposite each other - two displays opposite each other" results in the fact that the unshielded fields emitted from the rear of the monitors cover the working place opposed. The Swedish Confederation of Professional Employees, TCO (Tjänstemännens Centralorganisation), has released an even stricter standard TCO 2 for electric and magnetic fields which, however, demands an elaborated manufacturing technology and therefore is mostly only observed by expensive monitors with more than 16 inches.

\section{Recycling}

Conditions for a practicable recycling are

- the use of recycling friendly substances,

- the reduced diversity of substances,

- a modular design which allows to dismantle the computer within briefest time (criterion: ca. $2 \mathrm{~min}$ ) into its basic components.

Compounds and mixed plastics make recycling a lot more difficult. Compounds for instance are weldings of plastic foams and plastic plates, which were used in former times for the housing construction. Mixtures of plastics are not always recyclable. For instance it is not possible to simply mold granules in order to produce new and high quality substances with selected features. Here the solution is the downcycling to the well know forms of noise barriers and park benches.

The most renowned manufacturers produce the housings - as mentioned in chapter 2.1 - using either metal or one, at most two kinds of plastics. In this way the requirements of the "Blue Angel" are met. However, some manufacturers are still occupied with the task to clearly mark the plastics used.

It seems important to note one fact: When the term "recycling plastics" is mentioned in advertising, in most cases this just means that during production the resulting waste is directly fed into to the production process again. The use of actually used plastics requires the approval of characteristics specific for the substance, which is considered as too expensive so far. An exception is the production of keyboard housings from used PVC by the company IBM.

Seen from the viewpoint of recycling, the packaging of computers also plays a major role. Here, the transport companies establish certain criteria, because otherwise they are not liable for possible damage. To absorb shocks during transport in most cases the lightweighted and reasonably priced, but not recyclable foamed polystyrol (EPS) is used, better known by its brand name styropor. Alternatives, which can be recycled better, are cardboard, corn chips or stiffened cotton canvas. Most challenging is the packaging of the monitor. Here we still cannot avoid the use of EPS. Finally the plastic bags used to protect against humidity and dust are a problem because paper is not an alternative in all cases, especially when the products are delivered from tropical countries.

A requirement for fast dismantling is to abstain from welding and soldering points as well as from so-called inserts (not separable metal plastics compounds). Furthermore screws should be used as sparsely as possible. Acer designs all its computers without using screws. Instead, everything is plugged, clicked or (via snap lock) snapped. 


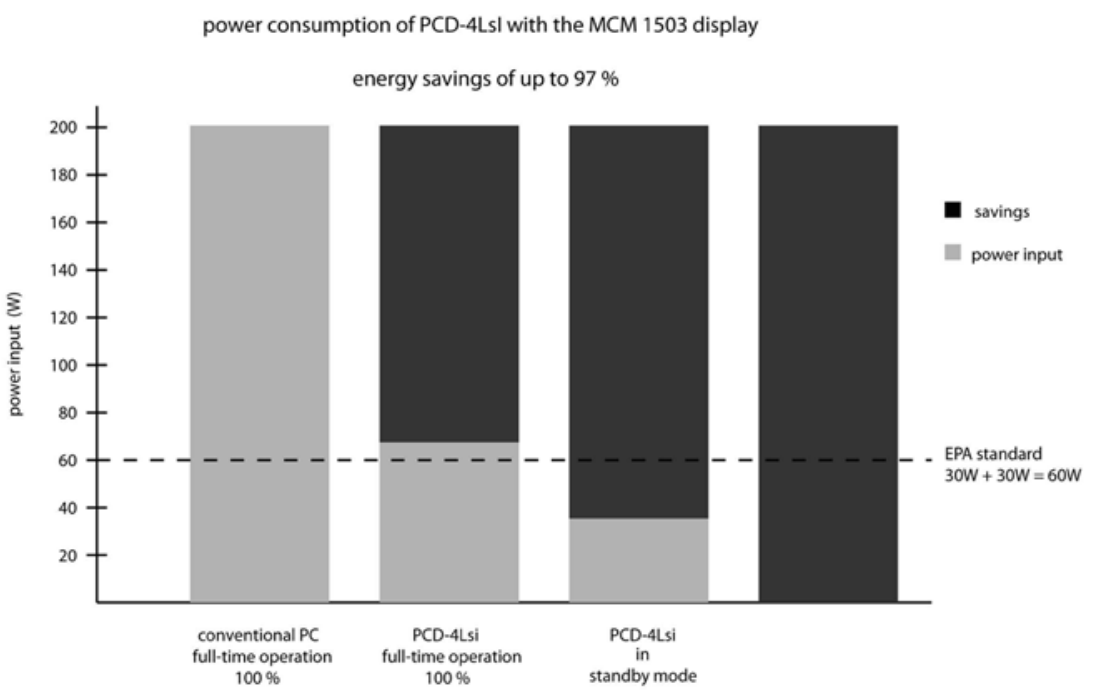

Fig. 2 Power consumption of the Siemens Nixdorf Eco-PC 4Lsl

\section{Saving energy and resources}

The U.S. American Environmental Protection Agency EPA has set standards for saving energy under the term "Energy Star". This attracted the media's attention for the green PC for the first time. Starting point was the power consumption of PCs switched on but not being in use, which has achieved significant dimensions in big companies and administrations. EPA demands a "low power state" in which the PC does not consume more than 30 Watt. Because the U.S. American Federal Authorities soon noticed that they could save public money by buying computers with lower power consumption, they ordered to purchase only products which are compliant with the EPA standards.

Also the requirements of the "Blue Angel" demand an energy saving mode. With appropriately designed computers, energy is saved via software so that i. e. hard disk drive and display are automatically switched off after a certain period of time of non usage and only the "essential" functions remain. Meanwhile manufacturers report a power consumption of only 5 Watt instead of 150 Watt or 200 Watt in former times (Fig. 2). However the best solution is to switch off the computer when it is not in use.

Resources can primarily be saved if the components are

- easy to repair and then to be built in again or

- to be taken from used equipment and used in new ones.

Fans, power supplies, and transformers are to be considered for re-usage.

\section{Outlook}

With the "Blue Angel" for computers a standard is set which the manufacturers will have to match their products to in future. This puts a stop to dishonest advertisements of the eco-PC. The criteria of the "Blue Angel" relate especially to recycling friendly design because this will be of importance for the upcoming electronic waste and scrap ordinance.

A problem with all computers is the short lifetime of the products. For the manufacturers inevitably there are no incentives to launch durable and therefore environmentally sound and resource considering products. The preliminary notes to the awarding requirements of the "Blue Angel" say: "Especially in the area of desktop computers the fast technological development leads to the replacement of devices with such of better performance in relatively short time periods. A steadily rising number of used devices need to be disposed of." And: "The eco label therefore should be applied to products which combine the potential durability of the system and its components with a recycling friendly design as well as with the possibility for re-usage and recycling of used products or product components."

Environmental groups like the BUND are not satisfied with the criteria of the "Blue Angel". The discussion about the green computer will therefore be continued in public, so that manufacturers will not be able to satisfy themselves with short-lived "display items", but are forced to continue the production of environmentally friendly products.

\section{References}

Behrend S (1994) Ökologisches Produzieren. Energie 4:17-21

na (1994) Chlor zu 70 Prozent ersetzbar. BUNDschau 1:24

Eder SW (1994) Es grünt so grün. Natur und Umwelt 2:20-23

Jury Umweltzeichen (eds) (1994) Grundlagen für die Umweltzeichenvergabe RAL-UZ 78, Umweltgerecht konstruierte Arbeitsplatz-Computer 